\title{
Distribution of immunoglobulin classes and IgG subclasses against a culture filtrate antigen of Burkholderia pseudomallei in melioidosis patients
}

\author{
V. CHENTHAMARAKSHAN, M. V. KUMUTHA, J. VADIVELU and S. D. PUTHUCHEARY \\ Department of Medical Microbiology, Faculty of Medicine, University of Malaya, 50603 Kuala Lumpur, \\ Malaysia
}

\begin{abstract}
The class and subclass distribution of antibody response to the culture filtrate antigen (CFA) of Burkholderia pseudomallei was examined in the sera of 45 septicaemic and 17 localised melioidosis cases and 40 cases clinically suspected of melioidosis and the results were compared with those from high-risk and healthy control groups. The geometric mean titre index (GMTI) values for all classes and subclasses of immunoglobulins examined were higher for sera from the proven and clinically suspected melioidosis cases than for the control groups. However, the highest response in the three patient groups was that of IgG with GMTIs ranging from 219.4 to 291.6 and the lowest was for IgM with GMTIs of 22.5, 24.3 and 28.7. The IgA response was intermediate with GMTIs ranging from 119.2 to 170 . The GMTIs were highest for IgG in septicaemic and localised infections and for IgA and IgM in localised infections. As regards IgG subclass distribution, IgG1 and IgG2 were the predominant subclasses produced against the CFA in contrast to IgG3 and IgG4, which were produced in low amounts. None of the sera from the control groups had any significant titres of antibodies.
\end{abstract}

\section{Introduction}

Melioidosis is an infectious disease of man and animals caused by a gram-negative saprophytic bacterium, Burkholderia pseudomallei. It presents in man in several forms ranging from inapparent infections, to wound infections, to acute septicaemia with a mortality rate of $>60 \%$ [1]. Although much is known about the epidemiology, clinical manifestations and the course of the disease and its response to antimicrobial agents, the host immune response towards the infection has still not been completely defined [2-4]. Bacterial antigens secreted or shed into the body would be among the first candidate molecules encountered by the host immune system. Very little is known of the isotypes of antibody produced against these secreted antigens in the host micro-environment. Although cell-mediated immune processes are likely to be necessary in immunity against bacteria, bactericidal and phagocytosis-promot-

Received 13 Aug. 1999; revised version accepted 2 May 2000.

Corresponding author: Dr J. Vadivelu (e-mail: jamuna@, medicine.med.um.edu.my). ing antibodies may have an important role in the initial clearance of the bacteria.

The major class of immunoglobulin produced in normal human serum is IgG and of its four subclasses, IgG1 amounts to $c$. $65 \%$ of the total $\operatorname{IgG}[5,6]$. Certain antigens elicit immunoglobulin production restricted to only some of the three major classes, i.e., IgG, IgM, and IgA and perhaps some of the four IgG subclasses [7]. Selective deficiency of one or more of the IgG subclasses could increase susceptibility to recurrent infections or allow an existing infection to be prolonged $[8,9]$. On the other hand, the selective increase in one or other class or subclass of antibody may aid the host in eliminating the existing infection and protect against recurrent infection or re-infection. Current knowledge on the antibody isotype distribution in melioidosis patients is poor and restricted to antilipopolysaccharide antibody response [10]. Further information on the antibody isotype distribution will aid in the development of a good assay system for diagnosis and monitoring the progression of the disease. The aim of the present study was to determine the immunoglobulin class and IgG subclass distribution against a $B$. pseudomallei culture filtrate antigen (CFA) in patients with melioidosis. 


\section{Materials and methods}

\section{Bacterial strain}

B. pseudomallei (CMS01859) isolated from the blood of a patient with melioidosis was used in this study.

\section{Serum specimens}

Sera were collected from 45 patients with septicaemic melioidosis, 17 patients with localised melioidosis and 40 patients with clinically suspected melioidosis, at the University Hospital, University of Malaya, Kuala Lumpur and various other hospitals in East and West Malaysia. All septicaemic and localised melioidosis cases were bacteriologically confirmed from blood culture or pus samples and serum samples were collected soon after diagnosis (2-3 days). All the clinically suspected melioidosis cases were diagnosed as fever of unknown origin and results were negative for other infections endemic in the areas such as tuberculosis, typhoid, leptospirosis, typhus and rickettsial fevers. Serum samples from these cases were collected c. 1-3 weeks after onset of illness. In addition, these cases had clinical features suggestive of melioidosis such as prolonged fever, non-healing wounds and ulcers in diabetic patients, communityacquired pneumonia, abscesses, cellulitis, empyema and pleural effusions but did not have specimens available for culture or the culture results were negative. Serum samples were also collected from 25 normal subjects from rural areas of Malaysia (high-risk group) and 15 blood donors from the Kuala Lumpur metropolitan area (healthy control group).

\section{Culture filtrate antigen (CFA)}

B. pseudomallei was grown in protein-free Sauton's medium supplemented with L-asparagine $0.4 \%$. The culture filtrate antigen (CFA) was prepared and concentrated from the spent media of a 24-h culture of B. pseudomallei as described previously [11]. The concentrate was dialysed $(12-14 \mathrm{kDa})$ overnight against $0.01 \mathrm{M}$ phosphate-buffered saline $(\mathrm{pH} 7.2)$ and the protein concentration was estimated by the method of Lowry [12] after which sodium azide $0.05 \%$ was added. The preparations were stored at $-20^{\circ} \mathrm{C}$ until use.

\section{ELISA for immunoglobulin classes and subclasses}

ELISAs for IgG, IgM, IgA and IgG subclasses were performed as described earlier $[13,14]$ with minor modifications. CFA concentration and dilution of conjugates were optimised by checkerboard titration. The CFA was applied at a concentration of $100 \mathrm{ng} /$ well in $100 \mu \mathrm{l}$ of $0.05 \mathrm{M}$ Tris-buffered saline (TBS), $\mathrm{pH}$ 8.6, in MaxiSorp polystyrene flat-bottomed microtitration plates (Nunc, Denmark) and incubated overnight at $4^{\circ} \mathrm{C}$. The wells were then blocked for $1 \mathrm{~h}$ at $37^{\circ} \mathrm{C}$ with bovine serum albumin (Sigma) 1\% after which the test sera, serially double-diluted from an initial dilution of 1 in 25 in PBS supplemented with Tween $20 \quad 0.05 \%$ (PBS/T), were added to duplicate wells and incubated at $37^{\circ} \mathrm{C}$ for $2 \mathrm{~h}$. Horseradish peroxidase-labelled goat anti-human $\operatorname{IgG}, \operatorname{IgM}$ or $\operatorname{IgA}$ conjugate (Sigma) in $\mathrm{PBS} / \mathrm{T}$ was then added and incubated at $37^{\circ} \mathrm{C}$ for $2 \mathrm{~h}$. Tetramethylbenzidine substrate (Sigma) $0.05 \%$ in citrate phosphate buffer, $\mathrm{pH} 6$, and $\mathrm{H}_{2} \mathrm{O}_{2} \quad 0.001 \%$ was used for detection of the enzyme reaction. The reaction was stopped after $10 \mathrm{~min}$ by the addition of $1 \mathrm{~N} \mathrm{HCl}$ and the OD values were read with a multi-scan ELISA reader at a wavelength of $450 \mathrm{~nm}$. An OD value of 0.05 above the nullified background (blank wells) OD was considered as reactive for specific antibodies and the highest reactive dilution was considered to be the endpoint titre. Samples that gave OD values greater than the mean OD $+3 \mathrm{SD}$ of serum samples from healthy individuals at the cut-off dilution were considered as positive. The cut-off dilution was that which excluded all healthy controls. The geometric mean titre (GMT) for each patient group was calculated with SSPS software application, and as these values were very high, a geometric mean titre index (GMTI) was calculated by dividing the GMT of each patient group by the GMT value of the normal control group. Serum from a patient with culture-positive melioidosis was used as the positive control in all plates and an interassay variation of $<10 \%$ was considered acceptable.

For the detection of IgG subclass antibodies, the ELISA was performed as above except that a biotinstreptavidin system was used. After incubation of the CFA with the test sera, optimally diluted biotin-labelled mouse anti-human IgG1, IgG2, IgG3 and IgG4 monoclonal antibodies (MAbs) (Sigma) in PBS/T supplemented with bovine serum albumin $1 \%$ were added and incubated at $37^{\circ} \mathrm{C}$ for $2 \mathrm{~h}$. Optimally diluted horseradish peroxidase-labelled streptavidin (Sigma) was added and incubated at $37^{\circ} \mathrm{C}$ for a further $2 \mathrm{~h}$. The GMT and GMTI values were calculated as described above.

\section{ELISA for antigen-specific IgE}

The ELISA for CFA-specific IgE antibody was performed as described by van Knapen et al. [15] with minor modifications. Briefly, the wells of microtitration plates were coated with CFA, blocked and stored as described above. For the assay, $100 \mu 1$ of serially double-diluted sera (from 1 in 25 in PBS/T supplemented with fetal calf serum $2 \%$ ) was added and allowed to react with the antigen at $37^{\circ} \mathrm{C}$ for $2 \mathrm{~h}$. The plates were then washed three times with $\mathrm{PBS} / \mathrm{T}$ and incubated further with optimal dilution of anti-human IgE-alkaline phosphatase (Sigma) in $0.05 \mathrm{M} \mathrm{TBS}, \mathrm{pH}$ 7.4 , supplemented with fetal calf serum $2 \%$ for $2 \mathrm{~h}$ at $37^{\circ} \mathrm{C}$. The wells were washed three times with TBS supplemented with Tween $200.05 \%$ and incubated with $5 \mathrm{mM} p$-nitrophenyl phosphate in sodium acetate buffer supplemented with $1 \mathrm{mM} \mathrm{MgCl} 2$ for a further $30 \mathrm{~min}$ at 
$37^{\circ} \mathrm{C}$. The enzyme reaction was read at $405 \mathrm{~nm}$ with a multi-scan ELISA plate reader and a nullified OD value $>0.05$ was considered as reactive for antigenspecific IgE antibodies.

\section{Results}

The ELISA results are expressed as percentage positivity of the different classes and subclasses of antibodies in the various groups of the study population (Table 1). In the localised melioidosis group, the percentage positivity was found to be $100 \%$ for $\operatorname{IgG}$ and $\operatorname{IgA}$ and $85 \%$ for IgM. The septicaemic group showed a positivity of $96 \%$ for $\operatorname{IgG}$ and $89 \%$ for $\operatorname{IgA}$, but only $66 \%$ for IgM. The positivity rates for the clinically suspected cases were similar, $94 \%$ for $\mathrm{IgG}$ and $86 \%$ for $\operatorname{IgA}$, but $\operatorname{IgM}$ was higher at $84 \%$, similar to the localised infections.

The titres for $\operatorname{IgG}, \operatorname{IgA}$ and $\operatorname{IgM}$ were found to vary from 100 to 409600 (Fig. 1). The GMTI values were calculated for each patient group. The values for both IgG and IgA were significantly higher than those recorded for $\operatorname{IgM}(p<0.005)$ (Table 2). The GMTI for IgG was 292 for septicaemic, 245 for localised infections and 219 for the clinically suspected cases. The GMTI values for IgA were intermediate, 150 for septicaemic cases, 170 for localised melioidosis and 119 for the clinically suspected cases, whereas for IgM the values were as low as 23 for the septicaemic cases, 24 for the localised melioidosis cases and 29 for the clinically suspected group. The low GMTI value of IgM antibodies was due to elevated levels of antigenspecific IgM antibodies in control groups, whose titres varied from 50 to 3200; however, the $\operatorname{IgG}$ and $\operatorname{IgA}$ antibody levels were $<100$ in the non-melioidosis groups. In summary, the mean levels of $\operatorname{IgG}, \operatorname{IgA}$ and IgM in the melioidosis groups, which included the clinically suspected cases, were significantly higher than those in the high-risk and healthy control groups ( $\mathrm{p}<0.001, \mathrm{p}<0.005$ and $\mathrm{p}<0.01$, respectively). Antigen-specific IgE antibody was not detected in either the meliodosis or the control sera (results not shown).
All four subclasses of IgG antibodies were detected in the sera of all melioidosis patients and the clinically suspected group. Among septicaemic cases $87 \%$ had IgG1 and $93 \%$ had IgG2 and among those with localised infections $94 \%$ had IgG1 and $88.5 \%$ IgG2 (Table 1). The clinically suspected group had IgG1 and IgG2 in $96 \%$ and $94 \%$, respectively. However, IgG3 was present in only $52 \%$ of septicaemic, $53 \%$ of localised and $48 \%$ of clinically suspected cases and IgG4 was present in 60,84 and $67.5 \%$ of cases, respectively. Levels of $\mathrm{IgG} 3$ and $\mathrm{IgG} 4$ were significantly lower than those of IgG1 and IgG2 $(\mathrm{p}<0.05)$, and were not detected in the sera of either the high-risk or the healthy control groups

The endpoint titres of IgG1 and IgG2 subclass antibodies varied from 100 to 409600 (Fig. 2). The GMTIs for IgG1 and IgG2 were higher in septicaemic cases (117 and 69, respectively), as compared with localised infections (90 and 55, respectively) (Table 2). The endpoint titres for IgG3 and IgG4 were also lower and varied from 50 to 10000 , in all the three melioidosis groups. The GMTIs for IgG3 and IgG4 antibodies in septicaemic, localised and clinically suspected cases were significantly higher $(p<0.05)$ than those in the control sera studied.

\section{Discussion}

The IgM and IgG responses to different antigens of $B$. pseudomallei in sera of patients with melioidosis have been examined by many workers and in general a high antibody level was observed [5, 16, 17]. Current knowledge on the antibody isotype distribution in melioidosis patients is restricted to anti-lipopolysaccharide antibody responses [10]. In the present study, class and subclass antibody responses to a CFA were analysed in melioidosis patients by ELISA. Serum samples from all three melioidosis groups had high levels of $\operatorname{IgM}, \operatorname{IgA}$ and IgG classes of antibodies in $66-100 \%$ of cases as compared with the control groups. Interestingly, the highest percentages for all three major classes of immunoglubulins were found among sera from localised infections, with IgA and $\operatorname{IgG}$ in $100 \%$ and $\operatorname{IgM}$ in

Table 1. Percentage positivity for immunoglobulin classes and IgG subclasses analysed by ELISA with CFA

\begin{tabular}{lcccccccc}
\hline & & \multicolumn{7}{c}{ Percentage positivity* } \\
\cline { 3 - 9 } & Total & IgG & IgA & IgM & IgG1 & IgG2 & IgG3 & IgG4 \\
Patient group & no. & $(400)$ & $(800)$ & $(6400)$ & $(200)$ & $(200)$ & $(200)$ & $(200)$ \\
\hline Septicaemic & 45 & 96 & 89 & 66 & 87 & 93 & 52 & 60 \\
Localised & 17 & 100 & 100 & 85 & 94 & 88.5 & 53 & 84 \\
Clinically suspected & 40 & 94 & 86 & 84 & 96 & 94 & 48 & 67.5 \\
High-risk group & 25 & 0 & 0 & 0 & 0 & 0 & 0 & 0 \\
Healthy controls & 15 & 0 & 0 & 0 & 0 & 0 & 0 & 0 \\
\hline
\end{tabular}

*Cut-off dilution for positivity (shown in parentheses) was the dilution which excluded all healthy controls. Samples giving OD values that were greater than the mean OD 3 SD of healthy controls at the cut-off dilution were considered positive. 


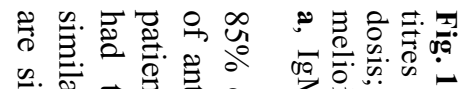

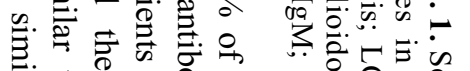

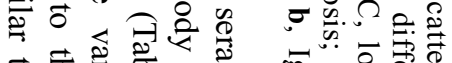

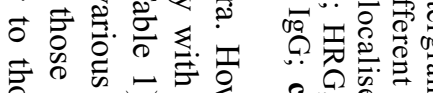

客

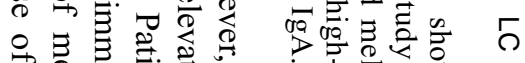

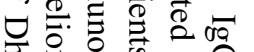

舟的学

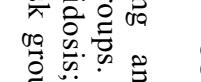

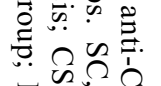

萡

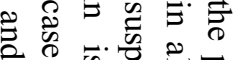

2

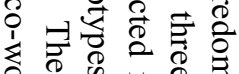

究

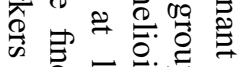

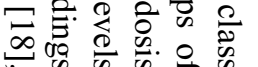

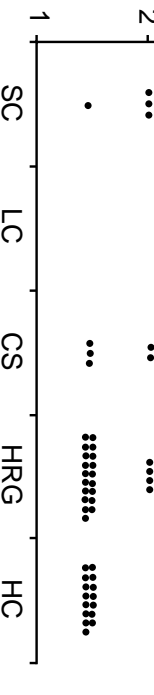

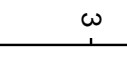

$\rightarrow$ G

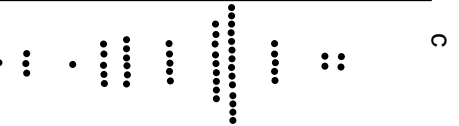

$\vdots \vdots \vdots \quad \cdots \quad \cdot \quad \cdot$

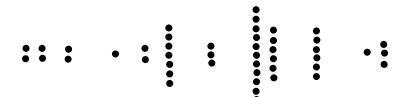

: :

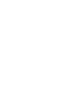

Antibody titre $\left(\log _{10}\right)$

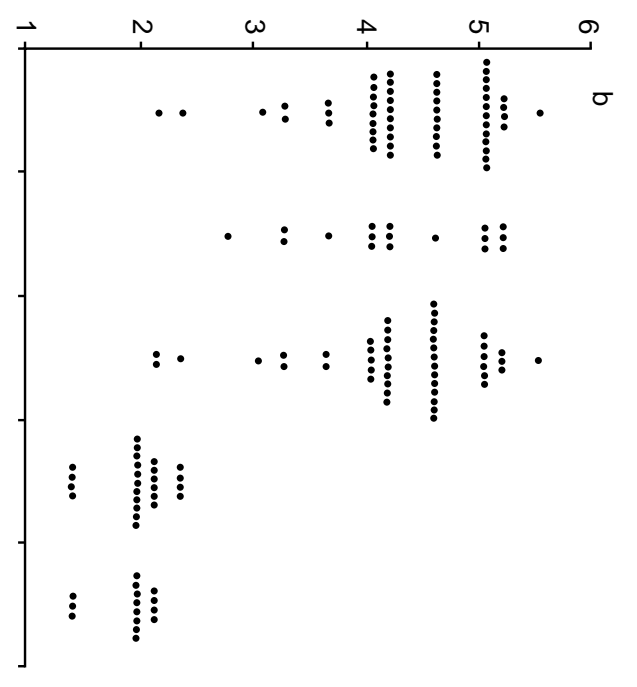

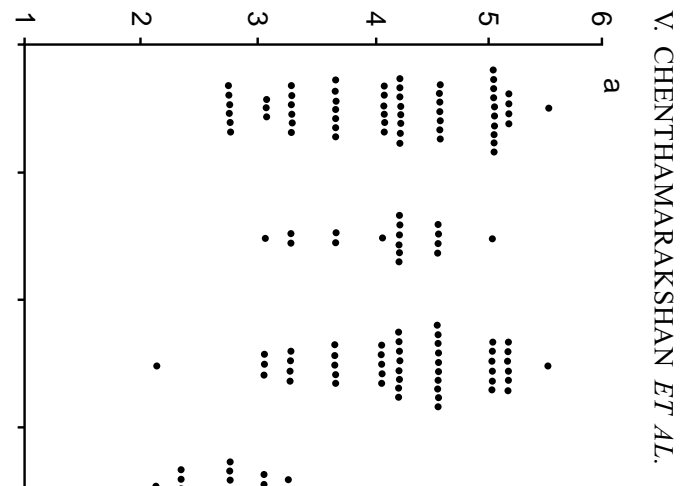

$:$

$: \vdots \vdots \vdots:$

Table 2. Geometric mean titre indices of immunoglobulin classes and subclasses

\begin{tabular}{|c|c|c|c|c|c|c|c|c|c|c|c|c|c|c|}
\hline \multirow[b]{2}{*}{ Patient group } & \multicolumn{2}{|c|}{ IgM } & \multicolumn{2}{|c|}{ IgG } & \multicolumn{2}{|c|}{ IgA } & \multicolumn{2}{|c|}{ IgG1 } & \multicolumn{2}{|c|}{ IgG2 } & \multicolumn{2}{|c|}{ IgG3 } & \multicolumn{2}{|c|}{ IgG4 } \\
\hline & GMTI* & $\mathrm{p}$ value & GMTI & $\mathrm{p}$ value & GMTI & $\mathrm{p}$ value & GMTI & $\mathrm{p}$ value & GMTI & $\mathrm{p}$ value & GMTI & $\mathrm{p}$ value & GMTI & $\mathrm{p}$ value \\
\hline Septicaemic & 22.5 & 0.0012 & 291.6 & 0.00015 & 149.8 & 0.0004 & 116.8 & 0.0007 & 68.7 & 0.0008 & 4.12 & 0.028 & 4.2 & 0.029 \\
\hline Localised & 24.3 & 0.001 & 244.5 & 0.00011 & 170 & 0.00022 & 89.5 & 0.0009 & 54.5 & 0.0008 & 6.8 & 0.014 & 9.2 & 0.008 \\
\hline Clinically suspected & 28.7 & 0.008 & 219.4 & 0.0001 & 119.2 & 0.00072 & 63.7 & 0.0015 & 75 & 0.0007 & 4.62 & 0.024 & 3.88 & 0.042 \\
\hline High-risk group & 1.19 & $\ldots$ & 1.38 & $\ldots$ & 1.218 & & 1.36 & & 0.73 & & 0.89 & $\ldots$ & 1 & $\ldots$ \\
\hline Healthy controls & 1 & $\ldots$ & 1 & & 1 & & 1 & & 1 & & 1 & & 1 & $\ldots$ \\
\hline
\end{tabular}

${ }^{*}$ Geometric mean titre index was calculated by dividing geometric mean value (GMT) for each antibody type by the respective GMT value of healthy controls. 

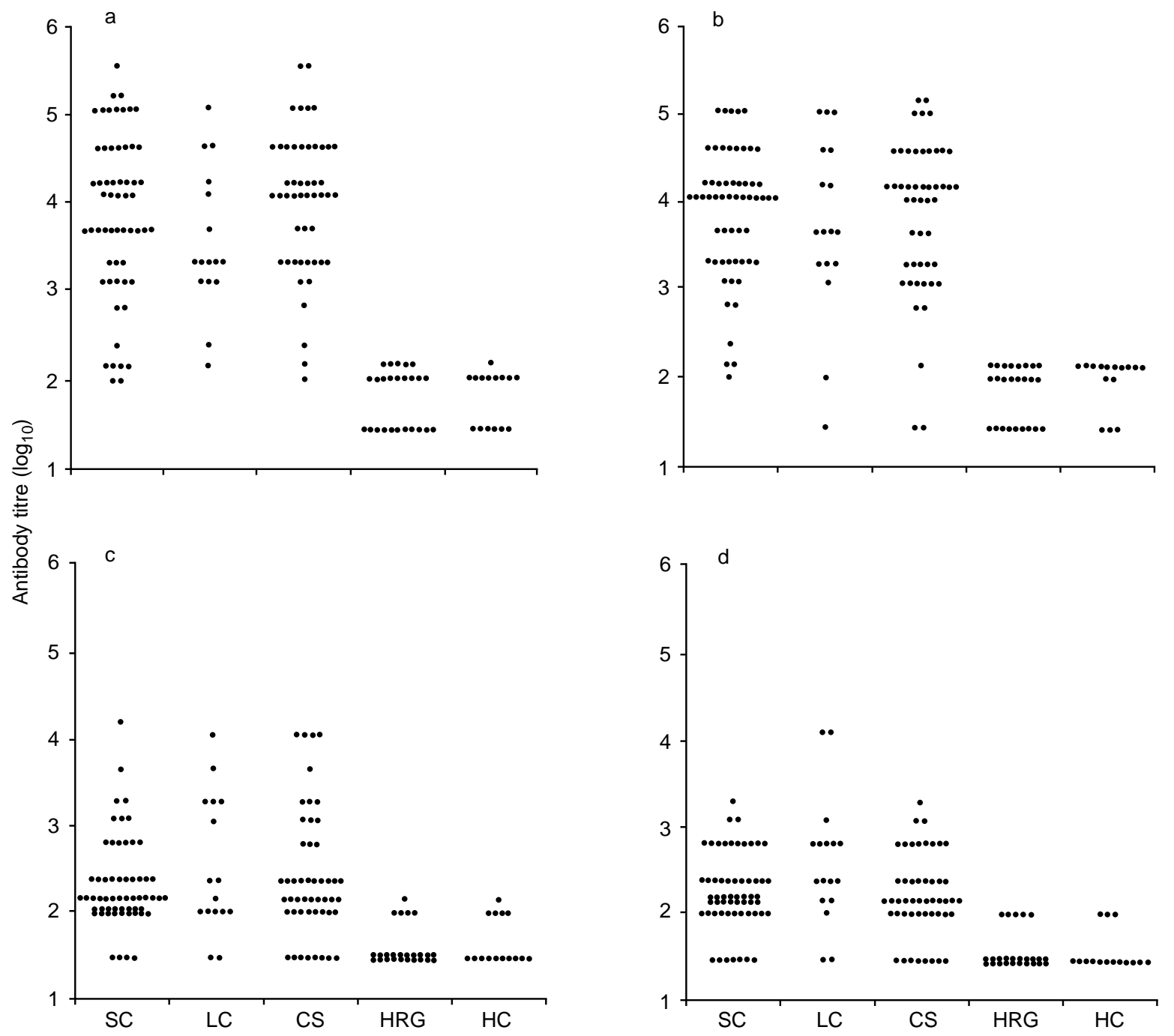

Fig. 2. Scattergram showing anti-CFA IgG subclass titres in different study groups. SC, septicaemic melioidosis; LC, localised melioidosis; CS, clinically suspected melioidosis; HRG, high-risk group; HC, healthy controls. a, IgG1; b, IgG2; c, IgG3; d, IgG4.

who demonstrated a higher detection rate for $\operatorname{IgG}$ antibodies in $82 \%$ of cases on days $0-5$ after admission. In contrast, IgM antibody was found in $60 \%$ of cases. Similarly among septicaemic cases, IgG was found in $88 \%$ of cases and $\operatorname{IgM}$ in $65 \%$. These findings lend further support to the fact that the detection of IgG to B. pseudomallei antigen was far superior to the detection of IgM for the early diagnosis of melioidosis.

In post-septicaemic melioidosis patients under maintenance therapy, elevated levels of IgM antibodies were maintained throughout the observation period (unpublished observations). The incubation period and duration of illness among septicaemic cases is not accurately known. However, among the localised infection group it may be possible to estimate the incubation period, especially in post-trauma sepsis and abscesses. The secretory antigens used in the present study consisted mainly of polysaccharides, which are thymus-independent antigens known to activate B cells to elicit low affinity IgM, and proteins (unpublished observations). These antigens, especially those of a polysaccharide nature, can persist for a long time in the lymphoid tissues and continue to stimulate newly maturing B cells in the production of IgM, which may then later be switched to other isotypes. At the same time these antigens could be continuously sequestered from intracellular organisms, thus priming the immune response.

In another study with lipopolysaccharide as the antigen, it was reported that IgM antibodies were detected only in localised melioidosis cases but not in septicaemic cases [10]. Interestingly, the present study showed that patients with localised infections, which were superficial soft tissue infections, had the highest levels of IgA in addition to IgM antibodies. Although very little is known about the humoral response in skin, secretory $\operatorname{IgA}$ is known to be present in skin secretions. As B lymphocytes are rarely present in cutaneous tissue, it may be possible that IgA produced by B cells activated in the draining lymph nodes is transported back to the skin via the circulation [19]. 
Previous reports have shown that, in general, only IgG and IgA antibodies activate neutrophils for mediator release and induction of phagocytosis of bacteria coated with antibodies of these classes [20]. IgG and $\operatorname{IgA}$, but not $\operatorname{IgM}[21]$, were also found to induce the release of significant levels of $\beta$-glucuronidase by neutrophils. Human $\operatorname{IgM}$ is known to activate the classical complement pathway, whereas $\operatorname{IgA}$ and $\operatorname{IgE}$ activate the alternative complement pathway [22]. Bacterial antigens have also been reported to elicit IgE production either during infection or immunisation and the presence of $\operatorname{IgE}$ has been correlated with disease severity in other bacterial infections [20-24]. However, the current study failed to detect antigenspecific IgE antibodies in melioidosis patients, including those with fulminant sepsis, demonstrating the absence of allergenic antibody-specific epitopes in the CFA used in this study.

Although the hierarchy of levels of different immunoglobulin types was found to be $\operatorname{IgG}>\operatorname{IgM}>\operatorname{IgA}$ in both melioidosis and clinically suspected groups, the GMTI values demonstrated a different pattern, i.e., $\operatorname{IgG}>$ $\operatorname{IgA}>\operatorname{IgM}$. The difference in the hierarchy is due to the elevated level of reactive $\operatorname{IgM}$ as compared with $\operatorname{IgG}$ or IgA in sera of healthy individuals. This elevated IgM level in healthy controls may be due to continuous exposure to the organism in the environment. This observation also indicates that elevated levels of $\operatorname{IgM}$ antibodies are produced in melioidosis patients due to the presence of IgM-specific epitopes in the extracellularly secreted products and surface molecules of B. pseudomallei.

Analysis of $\operatorname{IgG}$ isotypes demonstrated that IgG1 followed by $\mathrm{IgG} 2$ were the predominant subclasses involved in the humoral immune response to $B$. pseudomallei infection in man. The hierarchy of antiCFA IgG subclass antibodies was IgG1 $>\operatorname{IgG} 2>$ $\mathrm{IgG} 3 \cong \mathrm{IgG} 4$. This finding reflects the preferential response of $\mathrm{IgG} 1$ and $\mathrm{IgG} 2$ to protein and carbohydrate epitopes of this antigen. It has been reported that carbohydrate antigens tend to induce immunoglobulin isotype-restricted responses to $\operatorname{IgM}$ and $\operatorname{IgG} 2[22,25]$ and that protein antigens induce IgG1 and $\operatorname{IgG} 3$ [26]. In human immunisation studies with pneumococcal vaccines, IgG2 has been found to be the predominant immunoglobulin subclass produced to polysaccharide antigens [18]. In another study, Ho and co-workers demonstrated a low IgG subclass response to O-PS I (lipopolysaccharide) of $B$. pseudomallei [10], but predominant levels of IgG1 and IgG2 subclass antibodies in sera of all patient groups studied, which was similar to the findings in the present study. An IgG3 response was seen only in survivors of septicaemic infection, while IgG4 was not detectable. Although the role of different subclasses of $\mathrm{IgG}$ antibodies in human melioidosis is not understood, human IgG1, IgG2 and IgG3 are known to activate the classical complement pathway. IgG1 and $\operatorname{IgG} 3$ are also known to bind to mononuclear cells, of which macrophages and monocytes have been implicated as the major cell population involved in cell-mediated immunity [27]. Phagocytosis is promoted when the cells bind with the opsonised micro-organisms through specialised receptors for IgG1 and $\mathrm{IgG} 3$ and $\mathrm{C} 3 \mathrm{~b}$ complement [28]. To this end it has been reported that sera from melioidosis patients do indeed mediate phagocytic killing by polymorphonuclear leucocytes, and the killing effect was enhanced by complement [10], giving credibility to the possible role of the subclasses of $\mathrm{IgG}$ in the immune response to $B$. pseudomallei infection.

In summary, this study has demonstrated that all immunoglobulin classes, except IgE, and IgG subclasses were present in the immune response mounted to secretory antigens of $B$. pseudomallei, and that IgG1 and $\mathrm{IgG} 2$ are the predominant subclasses produced against CFA. However, the reasons for the inefficiency of these antibodies in killing or clearing the pathogen in patients in vivo despite the elevated level are unclear. Further work is needed to determine the actual role of elevated IgG1 and IgG2 antibody levels in melioidosis cases. The findings also demonstrate the reliability and sensitivity of secretory antigens and $\mathrm{IgG}$ antibody detection for the diagnosis of melioidosis in an endemic area.

The Ministry of Science and Technology, Malaysia, IRPA R\&D grant no. 06-02-03-0315 funded this research.

\section{References}

1. Puthucheary SD, Parasakthi N, Lee MK. Septicaemic melioidosis: a review of 50 cases from Malaysia. Trans $R$ Soc Trop Med Hyg 1992; 86: 683-685.

2. Wilson JW, Ashdown LR, Richard MJ, Sutherland AD, Cade JF. Subacute pulmonary melioidosis in a temperate climate. Med J Aust 1987; 147: 95-96.

3. Suputtamongkol Y, Rajchanuwong A, Chaowagul W et al. Ceftazidime vs. amoxicillin/clavulanate in the treatment of severe melioidosis. Clin Infect Dis 1994; 19: 846-853.

4. Anuntagool N, Rugdech P, Sirisinha S. Identification of specific antigens of Pseudomonas pseudomallei and evaluation of their efficiencies for diagnosis of melioidosis. J Clin Microbiol 1993; 31: 1232-1236.

5. Pruksachartvuthi S, Aswapokee N, Tankerngpol K. Survival of Pseudomonas pseudomallei in human phagocytes. $J$ Med Microbiol 1990; 31: 109-114.

6. Morrin M, Reen DJ. Inhibition of the adherence of Pseudomonas aeruginosa to epithelial cells by IgG subclass antibodies. J Med Microbiol 1993; 39: 459-466.

7. Yount WJ, Kunkel HG, Litwin SD. Studies of the Vi $(\gamma 2 \mathrm{c})$ subgroup of $\gamma$-globulin. A relationship between concentration and generic type among normal individuals. J Exp Med 1967; 125: $177-190$.

8. Schur PH, Borel H, Gelfand EW, Alper CA, Rosen FS. Selective gamma-G globulin deficiencies in patients with recurrent infections. N Engl J Med 1970; 283: 631-634.

9. Stanley PJ, Corbo G, Cole PJ. Serum IgG subclasses in chronic and recurrent respiratory infections. Clin Exp Immunol 1984; 58: $703-708$.

10. Ho M, Schollaardt T, Smith MD et al. Specificity and functional activity of anti-Burkholderia pseudomallei polysaccharide antibodies. Infect Immun 1997; 65: 3648-3653.

11. Kumar S, Chenthamarakshan V, Reddy MV, Narang P, Gupta OP, Harinath BC. Detection of tuberculous IgG antibodies using Mycobacterium tuberculosis H37Ra, excretory/secretory 
antigen and tuberculin-purified protein derivative. Indian $J$ Exp Biol 1994; 32: 163-167.

12. Lowry $\mathrm{OH}$, Rosebrough NJ, Farr AL, Randall RJ. Protein measurement with the folin phenol reagent. J Biol Chem 1951; 193: $265-275$.

13. Goldblatt D, Seymour ND, Levinsky RJ, Turner MW. An enzyme-linked immunosorbent assay for the determination of human IgG subclass antibodies directed against Branhamella catarrhalis. J Immunol Methods 1990; 128: 219-225.

14. Pressler T, Pedersen SS, Espersen F, Høiby N, Koch C. IgG subclass antibodies to Pseudomonas aeruginosa in sera from patients with chronic Ps. aeruginosa infection investigated by ELISA. Clin Exp Immunol 1990; 81: 428-434.

15. van Knapen F, Franchimont JH, Verdonk AR, Stumpf J, Undeutsch K. Detection of specific immunoglobulins (IgG, $\operatorname{IgM}, \operatorname{IgA}, \operatorname{IgE}$ ) and total $\operatorname{IgE}$ levels in human trichinosis by means of the enzyme-linked immunosorbent assay (ELISA). Am J Trop Med Hyg 1982; 31: 973-976.

16. Kunakorn M, Petchelai B, Khupulsup K, Naigowit P. Gold blot for detection of immunoglobulin $\mathrm{M}$ (IgM) and IgG-specific antibodies for rapid serodiagnosis of melioidosis. $J$ Clin Microbiol 1991; 29: 2065-2067.

17. Ashdown LR, Johnson RW, Koehler JM, Cooney CA. Enzyme-linked immunosorbent assay for the diagnosis of clinical and subclinical melioidosis. J Infect Dis 1989; 160: $253-260$.

18. Dharakul T, Songsivilai S, Anunragool N et al. Diagnostic value of an antibody enzyme-linked immunosorbent assay using affinity-purified antigen in an area endemic for melioidosis. Am J Trop Med Hyg 1997; 56: 418-423.

19. Williams IR, Kupper TS. Immunity at the surface: homeostatic mechanisms of the skin immune system. Life Sci 1996; 58: 1485-1507.
20. Emre U, Sokolovskaya N, Roblin PM, Schachter J, Hammerschlag MR. Detection of anti-Chlamydia pneumoniae $\operatorname{IgE}$ in children with reactive airway disease. J Infect Dis 1995; 172: 265-267.

21. Dahlman A, Hanson LA, Telemo E, Dahlgren UI. Development of $\operatorname{IgE}$ antibodies and $\mathrm{T}$ cell reactivity against intestinal bacterial antigens in rats and the influence of feeding. Adv Exp Med Biol 1995; 371A: 497-500.

22. Spiegelberg HL. Biological role of different antibody classes. Int Arch Allergy Appl Immunol 1989; 90 Suppl 1: 22-27.

23. Henson PM, Johnson HB, Spiegelberg HL. Release of granule enzymes from human neutrophils stimulated by aggregated immunoglobulins of different classes and subclasses. J Immunol 1972; 109: 1182-1192.

24. Bunikowski R, Mielke M, Skarabis $\mathrm{H}$ et al. Prevalence and role of serum IgE antibodies to the Staphylococcus aureusderived superantigens SEA and SEB in children with atopic dermatitis. J Allergy Clin Immunol 1999; 103: 119-124.

25. Mineo JR, Camargo ME, Ferreira AW. Enzyme-linked immunosorbent assay for antibodies to Toxoplasma gondii polysaccharides in human toxoplasmosis. Infect Immun 1980; 27: $283-287$.

26. Beck L, Spiegelberg HL. The polyclonal and antigen-specific $\mathrm{IgE}$ and $\mathrm{IgG}$ subclass response of mice injected with ovalbumin in alum or complete Freund's adjuvant. Cell Immunol 1989; 123: 1-8.

27. Alexander MD. Specificity of Fc receptors on human monocytes for IgG1 and IgG3. Int Arch Allergy Appl Immunol 1980; 62: 99-103.

28. Khalife J, Dunne DW, Richardson BA et al. Functional role of human IgG subclasses in eosinophil-mediated killing of schistosomula of Schistosoma mansoni. J Immunol 1989; 142: $4422-4427$. 